\title{
Composição química e perfil de ácidos graxos de cinco diferentes cortes de novilhas mestiças (Nelore vs Charolês) ${ }^{1}$
}

\section{Chemical composition and fatty acids profile of five carcass cuts of crossbred heifers finished in feedlot}

\author{
Lívia Maria Araújo Macedo²; Ivor Martin do Prado \\ Juliana Martin do Prado ; Polyana Pizzi Rotta ${ }^{4}$; Rodolpho Martin do Prado \\ Nilson Evelázio de Souza ${ }^{5}$; Ivanor Nunes do Prado ${ }^{6 *}$
}

\begin{abstract}
Resumo
O objetivo do presente estudo foi comparar a composição química e perfil de ácidos graxos entre acém, alcatra, contrafilé, coxão mole e patinho de novilhas cruzadas ( $1 \frac{1}{2}$ Nelore $v s ~ 1 / 2$ Charolês) terminadas em confinamento. O patinho, coxão mole e contrafilé apresentaram maior percentagem $(\mathrm{P}<0,05)$ de umidade $(75,19 ; 73,87$ e $74,36 \%)$ e cinzas $(1,09 ; 1,08$ e $1,13 \%)$ em relação ao acém $(71,18$ e $0,93 \%)$ e alcatra $(71,58$ e 1,07\%), respectivamente. Por outro lado, as percentagens de lipídios totais do acém $(7,40 \%)$ e alcatra $(5,19 \%)$ foram superiores $(\mathrm{P}<0,05)$ aos observados no contrafilé $(2,42 \%)$, coxão mole $(1,76 \%)$ e patinho $(1,69 \%)$. O colesterol total do acém $(57,63 \mathrm{mg} / 100 \mathrm{~g}$ de músculo) foi superior $(\mathrm{P}<0,05)$ ao observado no contrafilé (49,71 mg/100 g de músculo) e coxão mole (46,55 mg/100 g de músculo). As percentagens de $\mathrm{C}$ 18:3 n-3, C 20:4 n-6, C 20:5 n-3, AGPI, $n$-6 e $n$-3 do patinho (0,98, 1,88, 0,74, 9,34, 7,61 e 1,73\%) foram superiores $(\mathrm{P}<0,05)$ às observadas no acém $(0,38,1,13 ; 0,39 ; 4,22 ; 3,45$ e $0,77 \%)$ e contrafilé $(0,53 ; 0,93$; $0,26 ; 5,16 ; 4,37$ e $0,79 \%)$, respectivamente. Desta forma, os cortes que apresentaram menores riscos à saúde humana com relação ao perfil de ácidos graxos, foram o contrafilé, o coxão mole e o patinho.

Palavras-chave: Carne, confinamento, cortes, novilhas, qualidade de carne
\end{abstract}

\begin{abstract}
This work was carried-out to study the chemical composition and fatty acids profile among chuck, rump, striploin, topside and knuckle from crossbred ( $1 / 2$ Nellore $\times 1 / 2$ Charolais) heifers finished in feedlot. The knuckle, striploin and topside showed higher $(\mathrm{P}<0.05)$ moisture $(75.19,73.87$ e $74.36 \%)$ and ash contents $(1.09 ; 1.08$ and $1.13 \%)$ than the chuck $(71.18$ e $0.93 \%)$ and rump $(71.58$ e $1.07 \%)$, respectively. On the other hand, lipid contents of chuck $(7.40 \%)$ and rump $(5.19 \%)$ were higher $(\mathrm{P}<0.05)$ than striploin $(2.42 \%)$, topside $(1.76 \%)$ and knuckle $(1.69 \%)$. The chuck cholesterol content $(57.63 \mathrm{mg} / 100 \mathrm{~g}$ of muscle) was higher $(\mathrm{P}<0.05)$ than striploin $(49.71 \mathrm{mg} / 100 \mathrm{~g}$ of muscle) and topside (46.55mg/100 g of muscle). The knuckle percentages of C 18:3n-3 (0.98\%), C20:4n-6 (1.88\%), C $20: 5 n-3(0.74 \%)$, AGPI $(9.34 \%), n-6(7.61 \%)$ and $n-3(1.73 \%)$ were higher $(\mathrm{P}<0.05)$ than the values observed on knuckle $(0.38 ; 1.13 ; 0.39,4.22 ; 3.45$ and $0.77 \%)$ and striploin $(0.53 ; 0.93 ; 0.26 ; 5.16 ; 4.37$ and $0.79 \%$ ). The cuts that would present lower risk to human health, in relation to fatty acids, would be the striploin, topside and knuckle.
\end{abstract}

Key words: Beef, cuts, feedlot, heifers, quality

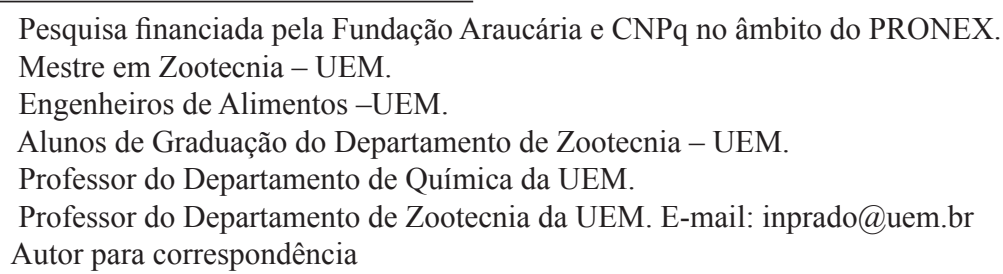




\section{Introdução}

A carne bovina consiste de músculo comestível, tecido conectivo e gordura associada, sendo seus mais importantes atributos de qualidade representados pela maciez, sabor, suculência, porção magra, quantidade de nutrientes, segurança e conveniência (PRADO, 2004). Contudo, há grande variação nos componentes químicos e físicos da carne de bovinos, a qual seria atribuída a fatores ligados à raça, sexo, idade, alimentação e localização anatômica do corte.

No sistema de comercialização predominante no Brasil, os quartos da carcaça são separados em aproximadamente 20 cortes comerciais (LUCHIARI FILHO, 2000).

Hopper (1944) observou que as composições físicas do corte comercializável da costela, e da porção comestível da $\underline{9}^{\mathrm{a}}-10^{\mathrm{a}}-11^{\mathrm{a}}$ costelas, foram correlacionadas com a composição física e com a porção comestível da carcaça como um todo. A partir dessa constatação, associou-se o músculo Longissimus como aquele que melhor poderia representar as características físicas e químicas dos músculos da carcaça de uma maneira geral. Contudo Shackelford, Wheeler, Koohmararaie (1995), ao avaliarem a correlação entre a maciez do Longissimus com a maciez de outros músculos da carcaça de bovinos, sugeriram que a indústria da carne deveria reavaliar o uso da maciez do contrafilé um geral da maciez de toda a carcaça.

Existe, na literatura, uma série de trabalhos buscando obter alterações no perfil de ácidos graxos e na composição físico-química do músculo Longissimus de bovinos, utilizando diferentes fontes de nutrientes na dieta (FRENCH et al., 2000; SCOLLAN et al., 2001; SILVA et al. 2001, 2002; PRADO et al, 2003; ABRAHÃO et al., 2005, PADRE et al., 2006; PRADO et al., 2008a), genótipos (VAZ et al., 2001; LABORDE et al., 2001; PADRE et al., 2006; PRADO et al., 2008b; c; d), pesos de abate (ARBOITTE et al., 2004), classes sexuais (VAZ et al., 2001) ou estado fisiológico
(MARQUES et al., 2006). Todavia, pouco se sabe sobre o efeito gerado, em função dessas variáveis, em outros cortes, senão o contra-filé.

O objetivo deste trabalho foi comparar a composição em umidade, cinzas, proteína bruta, lipídios totais, colesterol e ácidos graxos entre os cortes acém, alcatra, contrafilé, coxão mole e patinho, de novilhas cruzadas ( $1 / 2$ Nelore $v s 1 / 2$ Charolês), não gestantes, terminadas em confinamento.

\section{Material e Métodos}

$\mathrm{O}$ experimento de desempenho foi conduzido no setor de Bovinocultura de Corte da Fazenda Experimental de Iguatemi (FEI) pertencente à Universidade Estadual de Maringá (UEM). As análises químicas e de perfil de ácidos graxos foram realizadas no Laboratório de Análises de Alimentos pertencente ao Departamento de Química da Universidade Estadual de Maringá.

Foram utilizadas cinco fêmeas bovinas mestiças ( $1 \frac{2}{2}$ Nelore vs $1 / 2$ Charolês) com 20 meses de idade com peso corporal inicial médio de 317,26 \pm 14,29 kg e não gestantes, terminadas em confinamento.

Antes do início do experimento, as novilhas foram vacinadas contra febre aftosa, vermifugadas, identificadas com brincos plásticos e alojadas em um piquete de grama-estrela (Cynodon nlemfuensis), com $270 \mathrm{~m}^{2}$ e pouca arborização, cocho construído em concreto ( 2 metros lineares/animal) e bebedouro com capacidade para 250 litros. Após um período de adaptação de 12 dias, os animais foram confinados por 55 dias para a coleta de dados de desempenho.

Durante o período de confinamento (55 dias) as novilhas tinham livre acesso ao comedouro e bebedouro e foram alimentadas duas vezes por dia com uma dieta à base de silagem de milho, como volumoso, e farelo de soja, milho moído, casca de soja e mistura mineral (Tabela 1). 
Tabela 1. Composição da dieta experimental na matéria seca (MS, \%).

\begin{tabular}{lc}
\hline Componentes & MS, $\%$ \\
\hline Silagem de Milho & 39,00 \\
Milho moído & 21,00 \\
Farelo de Soja & 5,00 \\
Casca de Soja & 33,00 \\
Mistura Mineral & 0,60 \\
Calcário & 0,60 \\
Uréia & 0,80 \\
\hline Total & 100,00 \\
\hline
\end{tabular}

Adieta total foi composta por $61 \%$ de concentrado e 39\% de volumoso na base da matéria seca total, a água foi fornecida ad libitum. As novilhas foram alimentadas duas vezes por dia (8:00 e 16:00 horas), visando proporcionar um consumo por volta de $2,5 \%$ de $\mathrm{MS}$ em relação ao peso corporal. A dieta foi formulada segundo o National Research Council - NRC (1996), visando ganho de peso corporal de $1,0 \mathrm{~kg}$ ao dia. A determinação dos teores de nutrientes digestíveis (NDT) do farelo de soja, milho, casquinha de soja e silagem de milho baseou-se na composição dos alimentos, utilizando a equação para alimentos protéicos, energéticos e para casquinha de soja e silagem de milho a equação de alimentos volumosos, segundo Kearl (1982).
$\% \mathrm{NDT}=40,3227+0,5398 \%$ proteína bruta $(\mathrm{PB})+$ $0,448 \%$ extrato não nitrogenado $(\mathrm{ENN})+1,4218 \%$ extrato etéreo (EE) $-0,7007 \%$ fibra bruta (FB)

$\% \mathrm{NDT}=40,2625+0,1969 \% \mathrm{~PB}+0,4228 \% \mathrm{ENN}$ $+1,1903 \%$ EE-0,1379\% FB

$\% \mathrm{NDT}=-17,2649+1,2120 \% \mathrm{~PB}+0,8352 \% \mathrm{ENN}$ $+2,4637 \% \mathrm{EE}+0,4475 \% \mathrm{FB}$

Os animais tinham à disposição mistura mineral. A composição química dos componentes da dieta (\%MS) utilizados na formulação da dieta pode ser observada na Tabela 2.

As novilhas foram pesadas no início do experimento e posteriormente, a cada 28 dias, sendo as pesagens realizadas pela manhã, antes dos animais receberem a primeira alimentação do dia.

Tabela 2. Formulação da dieta e composição em percentagem da matéria seca (\%MS) dos nutrientes digestíveis totais (NDT), proteína bruta $(\mathrm{PB})$, fibra em detergente neutro $(\mathrm{FDN})$, extrato etéreo $(\mathrm{EE})$, cálcio $(\mathrm{Ca})$ e fósforo $(\mathrm{P})$ dos alimentos utilizados na dieta de novilhas cruzadas e confinadas.

\begin{tabular}{lccccccc}
\hline Componentes $(\%, \mathrm{~m} / \mathrm{m})$ & MS & NDT & PB & FDN & EE & Ca & P \\
\hline Silagem de milho & 27,00 & 60,00 & 7,90 & 59,00 & 3,00 & 0,25 & 0,22 \\
Milho & 88,64 & 80,00 & 7,00 & 9,00 & 3,70 & 0,02 & 0,31 \\
Casca de Soja & 92,50 & 72,00 & 11,30 & 68,56 & 1,36 & & \\
Farelo de Soja & 88,62 & 78,00 & 45,00 & 36,00 & & 0,50 & 0,20 \\
Calcário $^{\text {Mistura mineral }}{ }^{1}$ & 98,00 & & & & & 28,00 & \\
Uréia $^{98,00}$ & & & & & 23,00 & 17,00 \\
\hline
\end{tabular}

${ }^{1}$ Níveis de garantia/kg do produto: cálcio (Mín.)-130g; fósforo (Mín.)-65g; enxofre-12g; magnésio-12g; sódio-135g; cobre-1.155mg; zinco-3.050mg; manganês $1.050 \mathrm{mg}$; cobalto-63mg; iodo-63mg; selênio-18,20mg; ferro-2.680mg; flúor (máx.) 650mg; solubilidade do fósforo em ácido cítrico $2 \%$ (min) $95 \%$. 
Ao final do experimento de desempenho, as novilhas foram pesadas, após jejum de 14 horas e encaminhadas a um frigorífico comercial para serem abatidas.

Após o abate, as meia carcaças foram identificadas, pesadas e conduzidas para câmara de resfriamento, onde foram mantidas a $4^{\circ} \mathrm{C}$ por um período de 24 horas. Após o resfriamento, foram retiradas amostras do acém, alcatra, contrafilé, coxão mole e patinho, que foram em seguida identificadas e congeladas a $-20^{\circ} \mathrm{C}$ para posteriores análises. Desta forma, foram obtidas 5 amostras de cada corte comercial, provenientes das cinco novilhas utilizadas no experimento.

Após serem descongeladas em temperatura ambiente, as amostras (sem a gordura de cobertura) foram moídas para a determinação dos teores de umidade, cinzas e proteína bruta, segundo metodologia da Association of Official Analitical Chemistis - AOAC (1980). As análises foram realizadas em triplicata. A percentagem de lipídeos totais foi determinada segundo adaptação da metodologia de Bligh e Dyer (1959), e a transesterificação dos triacilgliceróis para obtenção dos ésteres metílicos de ácidos graxos foi realizada conforme o método ISO (1978). A extração do colesterol total foi realizada segundo método descrito por Al-Hasani, Hlavac e Carpenter (1993).

Os ésteres metílicos de ácidos graxos foram analisados por cromatografia gasosa, através de cromatógrafo gasoso Shimadzu 14-A, equipado com detector de ionização de chama e coluna capilar de sílica fundida (100 m de comprimento, $0,25 \mathrm{~mm}$ de diâmetro interno e 0,20 $\mu \mathrm{m}$ de CPSil88, ChromPack). Os fluxos dos gases foram de $1,2 \mathrm{~mL} / \mathrm{min}$ para o gás de arraste $\mathrm{H}_{2}, 30 \mathrm{~mL} / \mathrm{min}$ para o gás auxiliar $\mathrm{N}_{2}$, e 30 e $300 \mathrm{~mL} / \mathrm{min}$ para os gases da chama $\mathrm{H}_{2}$ e ar sintético, respectivamente. As temperaturas do injetor e detector foram $220 \mathrm{e}$ $245^{\circ} \mathrm{C}$, respectivamente. A temperatura da coluna foi de $180^{\circ} \mathrm{C}$, mantida por 5 minutos, sendo então elevada para $240^{\circ} \mathrm{C}$, a uma taxa de $4^{\circ} \mathrm{C} / \mathrm{min}$. A razão de divisão da amostra foi de 1:100. As áreas dos picos foram determinadas pelo método da normalização, utilizando um Integrador - Processador CG300, e a identificação dos picos foi realizada por comparação aos tempos de retenção de padrões de ésteres metílicos de ácidos graxos (Sigma).

A quantificação do colesterol total foi realizada por meio do cromatógrafo anteriormente citado, equipado com detector de ionização de chama e coluna capilar de sílica fundida $(25 \mathrm{~cm}$ de comprimento, 0,25 mm de diâmetro interno e 0,20 $\mu \mathrm{m}$ de SE-30). As temperaturas do injetor, detector e coluna, foram 260,300 e $300^{\circ} \mathrm{C}$, respectivamente. Os fluxos de gases foram: $1,5 \mathrm{~mL} / \mathrm{min}$ para o gás de arraste $\left(\mathrm{H}_{2}\right) ; 25 \mathrm{~mL} / \mathrm{min}$ para o gás make - up $\left(\mathrm{N}_{2}\right)$; $300 \mathrm{~mL} / \mathrm{min}$ para o ar sintético e $30 \mathrm{~mL} / \mathrm{min}$ para o $\mathrm{H}_{2}$ da chama. As áreas de pico foram determinadas por meio de Integrador-Processador CG-300, sendo a identificação do colesterol total efetuada por comparação com padrões Sigma (EUA).

Os dados de composição química, colesterol total e perfil de ácidos graxos dos diferentes cortes da carcaça, foram analisados por meio do programa SAEG(UNIVERSIDADE FEDERAL DE VIÇOSA, 1997) e as médias foram comparadas utilizando-se o teste de Tukey a 5\% de probabilidade. As análises estatísticas foram realizadas de acordo com o seguinte modelo:

$$
\mathrm{Y}_{\mathrm{ij}}=\mu+\mathrm{t}_{\mathrm{i}}+\mathrm{e}_{\mathrm{ij}}
$$

Onde:

$\mathrm{Y}_{\mathrm{ij}}=$ observação do corte i no animal j;

$\mu=$ constante geral;

$\mathrm{t}_{\mathrm{i}}=$ efeito do tipo de corte $\mathrm{i} ; \mathrm{i}=1 ; \ldots ; 5$;

$e_{i j}=$ erro aleatório associado a cada observação $Y_{i j}$.

\section{Resultados e Discussão}

A percentagem de umidade nos cortes contrafilé $(74,36 \%)$, coxão mole $(73,87 \%)$ e patinho $(75,13 \%)$ foram semelhantes $(\mathrm{P}>0,05)$ entre si e maiores 
$(\mathrm{P}<0,05)$ em relação às percentagens observadas nos cortes acém $(71,18 \%)$ e alcatra $(71,58 \%)$ (Tabela 3$)$.

As percentagens de cinzas foram semelhantes $(\mathrm{P}>0,05)$ entre os cortes alcatra $(1,07 \%)$, contrafilé $(1,13 \%)$, coxão mole $(1,08 \%)$ e patinho $(1,09 \%)$. Contudo, o corte acém $(0,93 \%)$, apresentou a menor $(\mathrm{P}<0,05)$ percentagem de cinzas.

A proteína bruta não apresentou diferença $(\mathrm{P}>0,05)$ entre os cortes (Tabela 3 ).
Ao contrário do observado nas demais variáveis, a percentagem de lipídios totais foi superior $(\mathrm{P}<0,05)$ nos cortes acém $(7,40 \%)$ e alcatra $(5,19 \%)$ em relação aos cortes contrafilé $(2,42 \%)$, coxão mole $(1,76 \%)$ e patinho $(1,69 \%)$. O colesterol do acém $(57,63 \mathrm{mg} / 100 \mathrm{~g}$ de músculo) foi superior $(\mathrm{P}<0,05)$ ao colesterol dos cortes contrafilé $(49,71$ $\mathrm{mg} / 100 \mathrm{~g}$ de músculo) e coxão mole $(46,55 \mathrm{mg} / 100 \mathrm{~g}$ de músculo). Os cortes alcatra $(53,72 \mathrm{mg} / 100 \mathrm{~g}$ de músculo) e patinho $(52,03 \mathrm{mg} / 100 \mathrm{~g}$ de músculo) não apresentaram diferença $(\mathrm{P}>0,05)$ entre si.

Tabela 3. Composição química de cinco cortes comerciais de novilhas mestiças $\left(1 / 2\right.$ Nelore $v s^{1 / 2}$ Charolês) terminadas em confinamento

\begin{tabular}{lccccc}
\hline & \multicolumn{5}{c}{ Cortes Comerciais } \\
\cline { 2 - 5 } Parâmetros & Acém & Alcatra & Contrafilé & Coxão Mole & Patinho \\
\hline Umidade, \% & $71,18 \pm 0,60 \mathrm{~b}$ & $71,58 \pm 0,60 \mathrm{~b}$ & $74,36 \pm 0,60 \mathrm{a}$ & $73,87 \pm 0,60 \mathrm{a}$ & $75,13 \pm 0,60 \mathrm{a}$ \\
Cinzas, \% & $0,93 \pm 0,01 \mathrm{~b}$ & $1,07 \pm 0,01 \mathrm{a}$ & $1,13 \pm 0,01 \mathrm{a}$ & $1,08 \pm 0,01 \mathrm{a}$ & $1,09 \pm 0,01 \mathrm{a}$ \\
Proteína bruta, \% & $20,96 \pm 0,15$ & $21,99 \pm 0,15$ & $21,18 \pm 0,15$ & $21,30 \pm 0,15$ & $21,33 \pm 0,15$ \\
Lipídios totais, \% $_{\text {Colesterol total }^{1}}^{7,40 \pm 0,04 \mathrm{a}}$ & $5,19 \pm 0,04 \mathrm{a}$ & $2,42 \pm 0,04 \mathrm{~b}$ & $1,76 \pm 0,04 \mathrm{~b}$ & $1,69 \pm 0,04 \mathrm{~b}$ \\
\hline
\end{tabular}

Médias seguidas de letras diferentes, na mesma linha, são diferentes pelo teste de Tukey $(\mathrm{P}<0,05)$.

${ }^{1} \mathrm{mg} / 100 \mathrm{~g}$ de músculo. Análises realizadas em base úmida.

Dentre os fatores que determinam variações no percentual de água da carne estão idade e grau de acabamento (DI MARCO, 1998; LUCHIARI FILHO, 2000), sexo (VAZ et al., 2001) e condição fisiológica (MARQUES et al., 2006). De modo geral, os valores de umidade observados na literatura para o músculo Longissimus, em bovinos terminados em diferentes sistemas de criação, têm variado de 71,22\% (MILLS et al., 1992) a 75,65\% (ABULARACH; ROCHA; FELICIO, 1998). A variação no teor de umidade também pode ocorrer em função do conteúdo de gordura total do músculo (MOREIRA et al., 2003). Quanto maior o teor de gordura no músculo, menor o teor de água. As percentagens de umidade observadas nos diferentes cortes estão dentro do observado na literatura. Além disso, a diferença observada nas percentagens de umidade entre os cortes foi pequena e poderia estar relacionada à percentagem de lipídios totais observados nos cortes. Segundo Di Marco (1998) a percentagem média de umidade observada para carnes magras está próximo de $75 \%$. Portanto, o patinho, o coxão mole e o contra-filé poderiam ser classificados dentro dos padrões de carne magra no que diz respeito à umidade.

A percentagem de cinzas nos tecidos cárneos encontra-se ao redor de 1\% (PRADO, 2004). A percentagem média observada para cinzas nos diferentes cortes $(1,06 \%)$ está próximo dos valores encontrados no músculo Longissimus sem gordura de cobertura de novilhos 1,04\% (MOREIRA et al.; 2003; ARICETTI et al., 2008), tourinhos $1,02 \%$ (ABRAHÃO et al.; 2005) e novilhas 1,10\% (MARQUES et al., 2006), criados em diferentes sistemas de terminação. Desta maneira, podese observar que independente do sexo, forma de terminação (pasto ou confinamento) e região anatômica do corte, o teor de cinza é pouco variável.

Da mesma forma, o teor de proteína total é pouco variável na carne bovina, sendo observado valores 
em torno de $20 \%$ da composição centesimal no músculo Longissimus sem a gordura de cobertura, independentemente da alimentação, raça, genótipo e condição fisiológica (SILVA et al., 2001; MENEZES et al., 2006; MOREIRA et al., 2003, ABRAHÃO et al., 2005, MARQUES et al., 2006). Na realidade, observou-se que independente da região anatômica em que se encontra o corte, o teor de proteína bruta ficou próximo do observado na literatura.

Por outro lado, existe grande variação na percentagem delipídios na carne bovina(LUCHIARI FILHO, 2000; MARQUES et al., 2006). O teor de lipídios é influenciado por vários fatores tais como sexo, raça e alimentação, bem como pela localização anatômica do corte cárneo (VAZ et al., 2001; RODRIGUES et al., 2004; SILVA et al., 2002; MOREIRA et al., 2003; USDA, 1999). Segundo Rodrigues et al. (2004) o teor de gordura na carne é de 3 a $5 \%$, podendo ser classificada como intracelular, intercelular e extracelular. Contudo, a percentagem de lipídios totais, observada nos diferentes cortes avaliados variou de 1,69\%, no patinho, a 7,40\% no acém. Essa variação pode ser devido à localização anatômica dos cortes, pois segundo Luchiari Filho (2000), a porcentagem de gordura também é extremamente variável nos diferentes músculos, com valores em torno de $2 \%$ nos da perna, chegando a $13 \%$ nos abdominais.

O baixo teor de gordura intramuscular pode prejudicar a suculência e a maciez do contrafilé, que é um corte de cocção rápida, quando cozido com calor seco (ABULARACH; ROCHA; FELICIO, 1998). Há evidências de que o conteúdo mínimo de lipídios necessário para se obter uma carne assada macia e suculenta seria de 2,9-3,0\% (CAMPION; CROUSE; DIKEMAN, 1975). Desta forma, os níveis de lipídios totais observados no coxão mole $(1,76 \%)$ e patinho $(1,69 \%)$ das novilhas foram inferiores ao que seria ideal para se obter uma carne assada macia. Estes cortes apresentam pouca gordura entremeada, provavelmente em função da localização atômica, o que caracteriza uma carne mais magra. Por outro lado, o teor de lipídios totais dos cortes de acém e alcatra estão acima dos valores observados na literatura para o músculo Longissimus de bovinos sem a gordura de cobertura (SILVA et al., 2001, 2002; COSTA et al., 2002; MOREIRA et al., 2003; ABRAHÃO et al., 2005; MARQUES et al., 2006). Maior deposição lipídica no músculo também pode estar relacionada à localização anatômica, embora a alcatra seja, assim como o coxão mole e patinho, um corte do quarto traseiro.

A variabilidade do percentual da gordura pode influenciar a proporção dos demais constituintes da carne (FELÍCIO, 1998; LUCHIARI FILHO, 2000; PARDI et al., 2001). Contudo, segundo Stromer, Goll e Roberts (1966), o teor de colesterol não está relacionado com a gordura de cobertura ou com o grau de marmorização da carne, como era de se esperar, mas sim com a quantidade de membranas celulares e estruturas intracelulares.

De maneira geral, os teores de colesterol observados nos diferentes cortes da carcaça das novilhas, estão acima do observado na literatura (COSTA et al., 2002; MOREIRA et al., 2003; MARQUES et al., 2006). Desta maneira, observase que há variação no teor de colesterol na carne de bovinos, a qual poderia ser atribuída a fatores como dieta, grau genótipo, sexo, condição fisiológica e também localização anatômica do corte.

O perfil de ácidos graxos dos cortes comerciais pode ser observado na Tabela 4. 
Tabela 4. Perfil de ácidos graxos do acém (ACM), alcatra (ALC), contrafilé (CTF), coxão mole (CXM) e patinho (PTN) de novilhas cruzadas $(1 / 2$ Nelore $v s 1 / 2$ Charles $)$ não gestantes terminadas em confinamento.

\begin{tabular}{|c|c|c|c|c|c|}
\hline \multirow[b]{2}{*}{ Ácidos Graxos } & \multicolumn{5}{|c|}{ Cortes Comerciais, \% } \\
\hline & $\mathrm{ACM}$ & ALC & CTF & CXM & PTN \\
\hline C 14:0 - Mirístico & $2,62 \pm 0,21$ & $2,06 \pm 0,21$ & $2,15 \pm 0,21$ & $1,84 \pm 0,21$ & $1,98 \pm 0,21$ \\
\hline C 16:0 - Palmítico & $25,20 \pm 0,61$ & $26,42 \pm 0,61$ & $26,97 \pm 0,61$ & $25,37 \pm 0,61$ & $25,91 \pm 0,61$ \\
\hline C 16:1 n 7 - Palmitoléico & $2,08 \pm 0,16$ & $2,65 \pm 0,16$ & $2,70 \pm 0,16$ & $2,40 \pm 0,16$ & $2,92 \pm, 016$ \\
\hline C 17:0 - Margárico & $1,07 \pm 0,04 \mathrm{a}$ & $0,97 \pm 0,04 \mathrm{ab}$ & $0,86 \pm 0,04 \mathrm{ab}$ & $0,93 \pm 0,04 \mathrm{ab}$ & $0,82 \pm 0,04 b$ \\
\hline C 17:1 n9-8-Heptadecenóico & $0,76 \pm 0,03$ & $0,79 \pm 0,03$ & $0,74 \pm 0,03$ & $0,78 \pm 0,03$ & $0,83 \pm 0,03$ \\
\hline C 18:0 - Esteárico & $21,25 \pm 0,57 \mathrm{a}$ & $16,85 \pm 0,57 b$ & $16,92 \pm 0,57 b$ & $16,09 \pm 0,57 b$ & $13,69 \pm 0,57 b$ \\
\hline C 18:1 (11t) - Transvacênico & $1,51 \pm 0,13$ & $1,20 \pm 0,13$ & $0,99 \pm 0,13$ & $1,29 \pm 0,13$ & $1,03 \pm 0,13$ \\
\hline C 18:1 $n 9$-Oléico & $39,19 \pm 0,73$ & $40,59 \pm 0,73$ & $41,24 \pm 0,73$ & $41,34 \pm 0,73$ & $40,85 \pm 0,73$ \\
\hline C 18:1 $n 7$ - Vacênico & $1,76 \pm 0,17$ & $1,39 \pm 0,17$ & $1,96 \pm 0,17$ & $2,29 \pm 0,17$ & $2,26+0,17$ \\
\hline C 18:2 n 6-Linoléico & $2,11 \pm 0,36 \mathrm{c}$ & $4,29 \pm 0,36 \mathrm{ab}$ & $3,33 \pm 0,36 \mathrm{bc}$ & $4,57 \pm 0,36 \mathrm{ab}$ & $5,62 \pm 0,36 \mathrm{a}$ \\
\hline C 18:3 n 3 - Linolênico & $0,38 \pm 0,08 b$ & $0,73 \pm 0,08 \mathrm{ab}$ & $0,53 \pm 0,08 b$ & $0,80 \pm 0,08 \mathrm{ab}$ & $0,98 \pm 0,08 \mathrm{a}$ \\
\hline C $18: 2(9 c-11 t)-$ CLA & $0,35 \pm 0,03$ & $0,35 \pm 0,03$ & $0,31 \pm 0,03$ & $0,37 \pm 0,03$ & $0,38 \pm 0,03$ \\
\hline C 20:4 n 6 - Aracdônico & $1,13 \pm 0,12 b$ & $1,20 \pm 0,12 \mathrm{ab}$ & $0,93 \pm 0,12 b$ & $1,37 \pm 0,12 \mathrm{ab}$ & $1,88 \pm 0,12 \mathrm{a}$ \\
\hline C 20:5 n 3 - Timnodônico & $0,39 \pm 0,05 \mathrm{~b}$ & $0,45 \pm 0,05 \mathrm{ab}$ & $0,26 \pm 0,05 b$ & $0,45 \pm 0,05 \mathrm{ab}$ & $0,74 \pm 0,05 \mathrm{a}$ \\
\hline
\end{tabular}

Médias seguidas de letras diferentes, na mesma linha, são diferentes pelo teste de Tukey $(\mathrm{P}<0,05)$.

${ }^{1}$ Coeficiente de variação.

O teor de ácido margárico $(\mathrm{C} 17: 0)$ foi superior $(\mathrm{P}<0,05)$ no corte acém $(1,07 \%)$ em relação ao patinho $(0,82 \%)$, e semelhante $(\mathrm{P}>0,05)$ aos teores observados nos cortes alcatra $(0,97 \%)$, contrafilé $(0,86 \%)$ e coxão mole $(0,93 \%)$.

A percentagem de ácido esteárico (C18:0) foi superior $(\mathrm{P}<0,05)$ no acém $(21,25 \%)$ em relação aos demais cortes: alcatra (16,85\%), contrafilé (16,92\%), coxão mole $(16,09 \%$ e patinho $(13,69 \%)$.

O teor de ácido linolênico (C 18:3n-3) observado no patinho $(0,98 \%)$ foi superior $(\mathrm{P}<0,05)$ aos observados nos cortes ácem $(0,38 \%)$ e contrafilé $(0,53 \%)$. Contudo, não houve diferença $(\mathrm{P}>0,05)$ entre a alcatra $(0,73 \%)$ e o coxão mole $(0,80 \%)$.

A percentagem do ácido graxo aracdônico $(\mathrm{C}$ 20:4 n-6), de cadeia longa no corte patinho $(1,88 \%)$ foi superior $(\mathrm{P}<0,05)$ ao observado no acém $(1,13 \%)$ e contrafilé $(0,93 \%)$ e não diferente $(P>0,05) \mathrm{em}$ relação às percentagens observadas nos cortes alcatra $(1,20 \%)$ e coxão mole $(1,37 \%)$.

O ácido timnodônico ou EPA (C 20:5 n-3), outro ácido graxo de cadeia longa, apresentou comportamento semelhante ao ácido aracadônico entre os cortes. O patinho $(0,74 \%)$ apresentou percentagem superior $(\mathrm{P}<0,05)$ aos cortes acém $(0,39 \%)$ e contrafilé $(0,26 \%)$. Contudo, não foi observada diferença $(\mathrm{P}>0,05)$ entre os cortes alcatra $(0,45 \%)$ e coxão mole $(0,45 \%)$ e patinho $(0,74 \%)$.

Os ácidos graxos predominantes nos cortes das novilhas foram o palmítico (C 16:0 - média de 25,97\%), esteárico (C 18:0 - média de 16,96\%) e oléico (C 18:1 n-9 - média de 40,64\%). Estes três ácidos graxos foram responsáveis por mais de $80 \%$ dos ácidos graxos identificados nos cortes. Dentre eles, apenas o ácido esteárico apresentou um aumento significativo em sua percentagem no acém (Tabela 4). Contudo, esse aumento não representa um risco em potencial no consumo deste corte, pois apesar de ser um ácido graxo saturado, o C 18:0 é considerado um ácido graxo neutro, não interferindo, portanto, nos níveis séricos de colesterol em seres humanos (BESSA, 1999; PRADO, 2004). O ácido margárico (C 17:0), apesar de estar presente em menores proporções, é um ácido graxo saturado e apresentou correlação positiva com a percentagem de lipídios totais dos cortes. 
Os ácidos linoléico (C 18:2 n-6) e alfa linolênico (C 18:3 n-3) são ácidos graxos poliinsaturados e classificados como essenciais, ou seja, devem ser ingeridos na alimentação, pois as células dos mamíferos não têm a capacidade de sintetizá-los (MOREIRA et al., 2003; SOUZA; VISENTAINER, 2006). Os ácidos linoléico e gama linolênico são precursores dos ácidos aracdônico (C 20:4 n-6) e EPA (C 20:5 n-3), ácidos graxos de cadeia longa formados através da ação de enzimas alongases e dessaturases presentes no retículo endoplásmatico das células (SOUZA; VISENTAINER, 2006). As percentagens dos ácidos graxos aracdônico e EPA no músculo Longissimus de bovinos podem variar em função da quantidade de lipídios totais na carne (MOREIRA et al., 2003). Contudo, as percentagens dos ácidos graxos aracdônico e EPA não foram totalmente correlacionadas com o teor de lipídios totais dos diferentes cortes, mas sim, correlacionadas entre si.
O total de AGPI observado no patinho (9,34\%) foi superior $(\mathrm{P}<0,05)$ aos cortes acém $(4,22 \%)$ e contrafilé $(5,16 \%)$. Não diferindo $(\mathrm{P}>0,05)$, no entanto em relação aos cortes alcatra $(6,81 \%)$ e coxão mole (7,30\%) (Tabela 5).

O mesmo comportamento pode ser observado para o total de ácidos graxos $n-6$ e $n-3$ nos cortes. Os totais de $n-6(7,61 \%)$ e $n-3(1,73 \%)$, respectivamente, do patinho foram superiores $(\mathrm{P}<0,05)$ aos totais observados nos cortes acém $(3,45 \%$ e $0,77 \%)$ e contrafilé $(4,37 \%$ e $0,79 \%)$ e não diferentes em relação aos cortes alcatra $(5,62 \%$ e $1,19 \%)$ e coxão mole $(6,06 \%$ e $1,73 \%)$.

A razão AGPI:AGS no corte patinho $(0,25)$ foi superior $(\mathrm{P}<0,05)$ à razão detectada no corte acém $(0,10)$, não diferindo, por outro lado, dos cortes alcatra $(0,18)$, contrafilé $(0,13)$ e coxão mole $(0,19)$.

Tabela 5. Teores de ácidos graxos poliinsaturados (AGPI), ácidos graxos monoinsatarados (AGMI), ácidos graxos saturados (AGS), ômega 6 (n-6), ômega 3 (n-3) e suas relações, no acém (ACM), alcatra (ALC), contrafilé (CTF), coxão mole (CXM) e patinho (PTN) de novilhas mestiças $\left(1 / 2\right.$ Nelore $v 1^{1} / 2$ Charolês) não gestantes terminadas em confinamento.

\begin{tabular}{lcccccc}
\hline \multirow{2}{*}{ Ácidos Graxos } & \multicolumn{5}{c}{ Cortes Comerciais } & \multirow{2}{*}{ CV $^{1}$} \\
\cline { 2 - 5 } & ACM & ALC & CTF & CXM & PTN & 15,23 \\
AGS, \% & 47,50 & 43,55 & 44,07 & 41,69 & 39,50 & 4,49 \\
AGMI, \% & 43,79 & 45,38 & 46,64 & 46,81 & 46,86 & 26,61 \\
AGPI, \% & $4,22 \mathrm{~b}$ & $6,81 \mathrm{ab}$ & $5,16 \mathrm{~b}$ & $7,30 \mathrm{ab}$ & $9,34 \mathrm{a}$ & 27,13 \\
$n-6, \%$ & $3,45 \mathrm{~b}$ & $5,62 \mathrm{ab}$ & $4,37 \mathrm{~b}$ & $6,06 \mathrm{ab}$ & $7,61 \mathrm{a}$ & 31,48 \\
$n-3, \%$ & $0,77 \mathrm{~b}$ & $1,19 \mathrm{ab}$ & $0,79 \mathrm{~b}$ & $1,25 \mathrm{ab}$ & $1,73 \mathrm{a}$ & 44,24 \\
AGPI/AGS & $0,10 \mathrm{~b}$ & $0,18 \mathrm{ab}$ & $0,13 \mathrm{ab}$ & $0,19 \mathrm{ab}$ & $0,25 \mathrm{a}$ & 22,25 \\
$n-6 / n-3$ & 4,65 & 4,83 & 5,60 & 4,91 & 4,59 & \\
\hline
\end{tabular}

Médias seguidas de letras diferentes, na mesma linha, são diferentes pelo teste de Tukey $(\mathrm{P}<0,05)$.

${ }^{1}$ Coeficiente de variação.

Os lipídios da carne de ruminantes, de maneira geral, são caracterizados por apresentar altas proporções de AGS e baixa razão AGPI:AGS (FRENCH et al., 2000). No entanto, Sinclair e O`Dea (1987) observaram que o músculo bovino com baixo teor de lipídios intramusculares também foi caracterizado pela baixa proporção de AGS e AGMI e alta proporção de AGPI. Deste modo, pode-se inferir que a localização anatômica do músculo influencia o total de AGPI, uma vez que nos cortes que apresentaram maior percentagem de AGPI observou-se menor percentagem de lipídios totais.

Apesar da baixa razão AGPI:AGS, a carne de ruminantes contém uma ampla variedade de AGPI, ambos das séries $n-6$ e $n$-3, que possuem potencial 
para melhorar a saúde humana (BANSKALIEVA; SAHLU; GOETSCH, 2000). Pode-se observar que os cortes que apresentaram menor percentagem de lipídios totais (patinho - 1,69\%, coxão mole $1,76 \%$ e contra-filé - $2,42 \%$ apresentaram as maiores percentagens de ácidos graxos das famílias $n-6$ e $n$ 3. Os ácidos graxos $n$ - 6 e $n-3$ são preferencialmente depositados nos fosfolipídios estruturais da membrana celular (PONNAMPALAM et al., 2001). Desta forma, acredita-se que a menor percentagem desses ácidos graxos poliinsaturados nos cortes com maior percentagem de lipídios totais, pode ter ocorrido devido à diluição dos fosfolipídios extraídos em meio aos lipídios encontrados entre as células.

Segundo HMSO (1994), a razão AGPI:AGS na dieta humana deveria estar em torno de 0,45 para evitar problemas de coração. Contudo, a razão AGPI:AGS é geralmente menor nos lipídios de ruminantes devido a biohidrogenação dos ácidos graxos insaturados da dieta pelos microorganismos do rúmen (BANSKALIEVA; SAHLU; GOETSCH, 2000; FRENCH et al., 2000). Embora todos os cortes tenham apresentado razão AGPI:AGS inferior à recomendada, os cortes com menor teor de lipídios totais se aproximaram mais do valor tido com ideal.

\section{Conclusão}

Os cortes que apresentaram melhor aspecto em relação ao seu possível efeito benéfico sobre a saúde humana foram o contrafilé, coxão mole e patinho em função do menor teor de colesterol e lipídios totais das maiores percentagens de ácidos graxos das famílias $n-6$ e $n-3$, AGPI e da melhor razão AGPI/AGS.

\section{Referências}

ABRAHÃO, J. J. S.; PRADO, I. N.; PEROTTO, D.; MOLETTA, J. L. Características de carcaça e da carne de tourinhos submetidos a dietas com diferentes níveis de substituição do milho por resíduo úmido da extração da fécula de mandioca. Revista Brasileira de Zootecnia, Viçosa, v. 34, n. 5, p. 1640-1650, 2005.
ABULARACH, M. L. S.; ROCHA, C. E.; FELICIO, P. E. Características de qualidade do contrafilé (músculo Longissimus dorsi) de touros jovens da raça nelore. Ciência e Tecnologia de Alimentos, Campinas, v. 18, n. 2, p. 205-210, 1998.

AL-HASANI, S. M.; HLAVAC, J.; CARPENTER, M. W. Rapid determination of cholesterol in single and multi-component prepared foods. Journal of Association of Official Analytical Chemists, Arlington, v. 76, n. 4, p. 902-906, 1993.

ARBOITTE, M. Z.; RESTLE, J.; ALVES FILHO, D. C. F.; BRONDANI, I. L.; PACHECO, P. S.; MENEZES, L. F. G.; PEROTTONI, J. Composição física da carcaça, qualidade da carne e conteúdo de colesterol no músculo Longissimus dorsi de novilhos 5/8 Nelore - 3/8 Charolês terminados em confinamento e abatidos em diferentes estádios de maturidade. Revista Brasileira Zootecnia, Viçosa, v. 33, n. 4, p. 959-968, 2004.

ARICETTI, J. A.; ROTTA, P. P.; PRADO, R. M.; PEROTTO, D.; MOLETTA, J. L.; MATSUSHITA, M.; PRADO, I. N. Carcass characteristics, chemical composition and fatty acid profile of Longissimus muscle of bulls and steers finished in a pasture system. AsianAustaliasian Journal of Animal Science, Seoul, v. 21, n. 10, p. 1441-1448, 2008.

ASSOCIATION OF OFFICIAL ANALITICAL CHEMISTIS - AOAC. Official methods of analysis. 14.ed. Arlington: AOAC, 1980.

BANSKALIEVA, V.; SAHLU, T.; GOETSCH, A. L. Fatty acid composition of goat muscles and fat depots: a review. Small Ruminant Research, Amsterdam, v. 37, n. 14, p. 255-268, 2000.

BESSA, R. J. B. Revalorização nutricional das gorduras dos ruminantes. In: SYMPOSIUM EUROPEO ALIMENTACIÓN EN EL SIGLO, 21.,1999, Olivença, Espanha. Anais... Badajoz: Colegio Oficial de Veterinarios de Badajoz, 1999. p. 283-313.

BLIGH, E. G.; DYER, W. J. A rapid method of total lipid extraction and purification. Canadian Journal of Biochemistry and Physiology, Ottawa, v. 37, n. 8, p. 911917, 1959.

CAMPION, D. R.; CROUSE, J. D.; DIKEMAN, M. E. Predictive value of USDA beef quality grade factors for cooked meat palatability. Journal of Food Science, Albany, v. 40, n. 6, p. 1225-1228, 1975.

COSTA, E. C.; RESTLE, J.; BRONDANI, I. L.; PEROTTONI, J.; FATURI, C.; MENEZES, L. F. G. Composição física da carcaça, qualidade da carne e conteúdo de colesterol no músculo Longissimus dorsi de novilhos Red Angus superprecoces, terminados em 
confinamento e abatidos com diferentes pesos. Revista Brasileira de Zootecnia, Viçosa, v. 31, supl. 1, p. 417428, 2002.

DI MARCO, O. N. Crescimiento de vacunos para carne. Buenos Aires: O autor, 1998.

FELÍCIO, P. E. Avaliação da qualidade da carne. In: SIMPÓSIO SOBRE PRODUÇÃO INTENSIVA DE GADO DE CORTE, 1., 1998, Campinas. Anais... São Paulo: Colégio Brasileiro de Nutrição Animal, 1998. p. 92-99.

FRENCH, P.; STANTON, C.; LAWLESS, F.; O'RIORDAN, E. G.; MONAHAN, F. J.; CAFFREY, P. J.; MOLONEY, A. P. Fatty acid composition, including conjugated linoleic acid of intramuscular fat from steers offered grazed grass, grass silage, or concentrate-based diets. Journal of Animal Science, Savoy, v. 78, n. 11, p. 2849-2855, 2000.

HMSO. Nutritional aspects of cardiovascular disease. London: Department of Health, 1994. (Report on Health and Social Subjects, 46).

HOPPER, T. H. Methods of stimating the physical and chemical composition of cattle. Journal of Agriculture Research, Washington, v. 68, n .6, p. 239-268, 1944.

INTERNATIONAL ORGANIZATION FOR STANDARDIZATION - ISO. ISO 5509: animal and vegetable fats and oils - preparation of methyl esters of fatty acids. Geneve: ISO, 1978.

KEARL, L. Nutrients requirements of ruminant in development countries. Logan: Utah State University, 1982.

LABORDE, F. L.; MANDELL, I. B.; TOSH, J. J.; WILTON, J. W.; BUCHANAN-SMITH, J. G. Breed effects on growth performance, carcass characteristics, fatty acid composition, and palatability attributes in finishing steers. Journal of Animal Science, Savoy, v. 79, n. 2, p. 355-365, 2001.

LUCHIARI FILHO, A. Pecuária da carne bovina. 2.ed. São Paulo: O autor, 2000.

MARQUES, J. A.; PRADO, I. N.; MOLETTA, J. L.; PRADO, I. M.; PRADO, J. M.; MACEDO, L. M. A.; SOUZA, N. E.; MATSUSHITA, M. Características físico-químicas da carcaça e da carne de novilhas submetidas ao anestro cirúrgico ou mecânico terminadas em confinamento. Revista Brasileira de Zootecnia, Viçosa, v. 35, n. 4, p. 1514-1522, 2006.

MENEZES, L. F. G.; KOZLOSKI, G. V.; RESTLE, J.; DESCHAMPS, F. C.; BRONDANI, I. L.; SANTOS, A. P.; FIAMONCINI, J. Perfil de ácidos graxos de cadeia longa e qualidade da carne de novilhos terminados em confinamento com diferentes níveis de monensina sódica na dieta. Ciência Rural, Santa Maria, v. 36, n. 1, p. 186190, 2006.

MILLS, E. W.; COMERFORD, J. W.; HOLLENDER, R.; HARPSTER, H. W.; HOUSE, B.; HENNING, W. R. Meat composition and palatability of Holstein and Beef Steers as influenced by forage type and protein source. Journal of Animal Science, Savoy, v. 70, n. 8, p. 24462451, 1992.

MOREIRA, F. B.; SOUZA, N. E.; MATSUSHITA, M.; PRADO, I. N.; NASCIMENTO, W. G. Evaluation of carcass characteristics and meat chemical composition of Bos indicus and Bos indicus x Bos taurus crossbred steers finished in pasture systems. Brazilian Archives of Biology and Technology, Curitiba, v. 46, n. 4, p. 609616, 2003.

NATIONAL RESEARCH COUNCIL - NRC. Nutrients requirements of beef cattle. 7.ed. Washington: National Academy Press, 1996.

PADRE, R. G.; ARICETTI, J. A.; MOREIRA, F. B.; MIZUBUTI, I. Y.; PRADO, I. N.; VISENTANIER, J. V.; SOUZA, N. E.; MATSUSHITA, M. Fatty acids profile, and chemical composition of Longissimus muscle of bovine steers and bulls finished in pasture system. Meat Science, Savoy, v. 74, n. 1, p. 242-248, 2006.

PARDI, M. C.; SANTOS, I. F.; SOUZA, E. R.; PARDI, H. S. Ciência, higiene e tecnologia da carne. 2.ed. Goiânia: Ed. da UFG, 2001. v. 2.

PONNAMPALAM, E. N.; SINCLAIR, A. J.; EGAN, A. R.; BKAKELEY, S. J.; LI, D.; LEURY, B. J. Effect of dietary modification of muscle long-chain $n-3$ fatty acid on plasma insulin and lipid metabolites, carcass traits, and fat deposition in lambs. Journal of Animal Science, Savoy, v. 79, n. 4, p. 895-903, 2001.

PRADO, I. N. Conceitos sobre a produção com qualidade de carne e leite. Maringá: Eduem, 2004.

PRADO, I. N.; ITO, R. H.; PRADO, J. M.; PRADO, I. M.; ROTTA, P. P.; MATSUSHITA, M.; VISENTAINER, J. V.; SILVA, R. R. The influece of dietary soyabean and linseed on the chemical composition and fatty acid profile of the Longissimus muscle of feedlot-finished bulls. Journal of Animal and Feed Sciences, Jablona, v. 17, n. 3, p. 307-317, 2008a.

PRADO, I. N.; PRADO, R. M.; ROTTA, P. P.; VISENTAINER, J. V.; MOLETTA, J. L.; PEROTTO, D. Carcass characteristics and chemical composition of the Longissimus muscle of crossbred bulls (Bos taurus indicus vs Bos taurus taurus) finished in feedlot. Journal of Animal and Feed Sciences, Jablona, v. 17, n. 3, p. 295 306, 2008b. 
PRADO, I. N.; ROTTA, P. P.; PRADO, R. M.; VISENTAINER, J. V.; MOLETTA, J. L.; PEROTTO, D. Carcass characteristics and chemical composition of the Longissimus muscle of Purunã and 1/2 Puruna vs. 1/2 Canchin bulls. Asian-Australiasian Journal of Animal and Feed Sciences, Seoul, v. 21, n. 9, p. 1296-1302, 2008 c.

PRADO, I. N.; ARICETTI, J. A.; ROTTA, P. P.; PRADO, R. M.; PEROTTO, D.; VISENTAINER , J. V.; MATSUSHITA, M. Carcass characteristics, chemical composition and fatty acid profile of the Longissimus muscle of bulls (Bos Taurus indicus vs. Bos Taurus Taurus) finished in pasture systems. Asian-Australiasian Journal of Animal and Feed Sciences, Seoul, v. 21, n. 10, p. $1449-1457,2008 \mathrm{~d}$.

PRADO, I. N.; MOREIRA, F. B.; MATSUSHITA, M.; SOUZA, N. E. Longissimus dorsi fatty acids composition of Bos indicus and Bos indicus x Bos taurus crossbred steers finished in pasture. Brazilian Archives of Biology and Technology, Curitiba, v. 46, n. 4, p. 601-608, 2003.

RODRIGUES, V. C.; BRESSAN, M. C.; CARDOSO, M. G.; FREITAS, R. T. F. Ácidos graxos na carne de búfalos e bovinos castrados e inteiros1. Revista Brasileira de Zootecnia, Viçosa, v. 33, n. 2, p. 434-443, 2004.

SCOLLAN, N. D.; CHOI, N. J.; KURT, E.; FISHER, A. V.; ENSER, M.; WOOD, J. D. Manipulating the fatty acid composition of muscle and adipose tissue in beef cattle. British Journal of Nutrition, London, v. 85, n. 1, p. 115-124, 2001.

SHACKELFORD, S. D.; WHEELER, T. L.; KOOHMARARAIE, M. Relationship between shear force and trained sensory panel tenderness ratings of 10 major muscles from Bos indicus and Bos taurus cattle. Journal of Animal Science, Savoy, v. 73, n. 11, p. 33333340, 1995.
SILVA, R. C.; PRADO, I. N.; MATSUSHITA, M.; SOUZA, N. E. Effects of substitution of corn by pulp citrous pellets on muscle fatty acid composition of finished heifeirs. Brazilian Chemistry Association, Campinas, v. 50, n. 4, p. 175-181, 2001.

SILVA, R. G.; PRADO, I. N.; MATSUSHITA, M.; SOUZA, N. E. Dietary effects on muscle fatty acids composition of finish heifers. Pesquisa Agropecuária Brasileira, Brasília, v. 37, n. 1, p. 95-101, 2002.

SINCLAIR, A. J.; O'DEA, K. The lipid levels and fatty acid composition of the lean portions of Australian beef and lamb. Food Technology, Sidney, v. 39, p. 228-231, 1987.

SOUZA, N. E.; VISENTAINER, J. V. Colesterol da mesa ao corpo. São Paulo: Varela, 2006.

STROMER, M. H.; GOLL, D. E.; ROBERTS, J. H. Cholesterol in subcutaneous and intramuscular lipid depots from bovine carcasses of different maturity and fatness. Journal of Animal Science, Savoy, v. 25, n. 4, p. 1145-1147, 1966.

UNIVERSIDADE FEDERAL DE VIÇOSA. SAEG: Sistema de Análises Estatísticas e Genéticas: versão 7.1: manual do usuário. Viçosa: Ed. da UFV, 1997.

UNITED STATE DEPARTMENT OF AGRICULTURE - USDA. Nutrient Database for Standard Reference, Release 13, NDB n. 10199. Washington, 1999.

VAZ, F. N; RESTLE, J.; FEIJÓ, G. L. D.; BRONDANI, I. L.; ROSA, J. R. P.; SANTOS, A. P. Qualidade e composição química da carne de bovinos de corte inteiros ou castrados de diferentes grupos genéticos Charolês $\mathrm{x}$ Nelore. Revista Brasileira de Zootecnia, Viçosa, v. 30, n. 2, p. 518-525, 2001. 
